11,09

\title{
Температурно-фазовая зависимость колебательного спектра и ориентационная подвижность тетрафторборат иона в органической соли н-Bu $4 \mathrm{NBF}_{4}$
}

\author{
(C) К.Ш. Рабаданов ${ }^{1}$, М.М. Гаффуров ${ }^{1}$, Н.Ф. Уваров ${ }^{2}$, А.С. Улихин ${ }^{2}$ \\ ${ }^{1}$ Дагестанский научный центр РАН, Аналитический центр коллективного пользования, \\ Махачкала, Россия \\ ${ }^{2}$ Институт химии твердого тела и механохимии СО РАН, \\ Новосибирск, Россия \\ E-mail: rksh83@mail.ru
}

(Поступила в Редакцию 27 марта 2018 г.)

\begin{abstract}
Методами колебательной спектроскопии исследованы структурно-динамические свойства тетрафторборат иона в органической соли н-Bu $\mathrm{NBF}_{4}$ при различных температурах и фазовых состояниях. По результатам расчетов энергетических и релаксационных параметров показано, что в пластической фазе $\mathrm{BF}_{4}^{-}$ион характеризуется низкой энергией переориентации по сравнению с кристаллической фазой.
\end{abstract}

Работа выполнена на оборудовании Аналитического центра коллективного пользования Дагестанского научного центра РАН.

DOI: $10.21883 /$ FTT.2018.12.46732.084

\section{1. Введение}

Исследования процессов релаксации колебательных возбуждений многоатомных ионов в ионных конденсированных системах на основе анализа формы контуров внутримолекулярных колебательных мод получили в последние годы заметное развитие [1-3]. На примере неорганических солей щелочных металлов было показано $[1,4,5]$ что спектральные и релаксационные параметры многоатомных анионов в них зависят от температуры и фазового состояния исследуемой системы, от формы, размера и зарядового состояния динамически взаимодействующих частиц. В этой связи представляет определенный интерес проанализировать указанные выше параметры в ионных системах, в которых как катионы, так и анионы являются многоатомными частицами. Органические соли замещенного аммония представляют для этой цели интересные объекты. Кроме того, высокотемпературные модификации многих органических соединений являются пластическими, ротационными или ориентационно-разупорядоченными фазами [6], а стерический фактор, т. е. характер взаимодействия элементов структуры, и, в частности, наличие анизотропного взаимодействия играют существенную роль в релаксации колебательных возбуждений сложных ионов в них.

Настоящая работа посвящена анализу температурных изменений спектральных параметров (частот, полуширин) и формы контуров колебательных полос, отвечающих внутренним колебаниям тетрафторборат иона $\mathrm{BF}_{4}^{-}$в спектрах инфракрасного поглощения и комбинационного рассеяния органической соли тетрафторборат тетра-н-бутиламмония при различных температурах и фазовых состояниях.

\section{2. Экспериментальная часть}

Тетрафторборат тетра-н-бутиламмония $\left(\left(\mathrm{C}_{4} \mathrm{H}_{9}\right)_{4} \mathrm{NBF}_{4}\right.$ или $\left.\mathrm{H}-\mathrm{Bu}_{4} \mathrm{NBF}_{4}\right)$ синтезировали с помощью обменных реакций из $\mathrm{H}-\mathrm{Bu}_{4} \mathrm{NBr}$ (х. ч.):

$$
2[\mathrm{H}-\mathrm{Bu} 4 \mathrm{~N}] \mathrm{Br}+\mathrm{Pb}\left(\mathrm{BF}_{4}\right)_{2} \rightarrow 2\left[\mathrm{H}-\mathrm{Bu}_{4} \mathrm{~N}\right] \mathrm{BF}_{4}+\mathrm{PbBr}_{2 \downarrow} .
$$

Полученный порошок дважды перекристаллизовывался в водно-спиртовых растворах и сушился при $120^{\circ} \mathrm{C}$. Образцы по указанной методике синтезированы в Институте химии и механохимии СО РАН.

Спектры ИК поглощения измерялись на ИК-Фурье спектрометре VERTEX-70 (фирма „Брукер“, Германия) c разрешением $1 \mathrm{~cm}^{-1}$. Спектры были получены путем усреднения 128 последовательных сканирований. Спектры комбинационного рассеяния света измерялись на конфокальном КР-микроскопе Senterra при лазерном возбуждении $(\lambda=785 \mathrm{~nm}$; мощность лазера $100 \mathrm{~mW}$ ); апертура $50 \times 1000 \mu \mathrm{m}$; спектральный диапазон $75-1530 \mathrm{~cm}^{-1}$ с разрешением $2-3 \mathrm{~cm}^{-1}$; используемый объектив микроскопа - $10 \times$; число сканов - 20; время интегрирования каждого скана $-20 \mathrm{~s}$.

Разделение сложных контуров колебательных полос на индивидуальные составляющие осуществлялось с использованием стандартного программного пакета OPUS 6.0. Форма полос аппроксимировалась кривыми вида свертки функций Гаусса и Лоренца. Подгонку расчетных кривых и исходного спектра с минимизацией абсолютной ошибки проводилось по методу Левенберга-Маркварта. Погрешность между расчетной и реальной кривой составляла $5-10 \%$ в зависимости от отношения сигнал/шум при записи исходного спектра. Температурные измерения проводились с использова- 

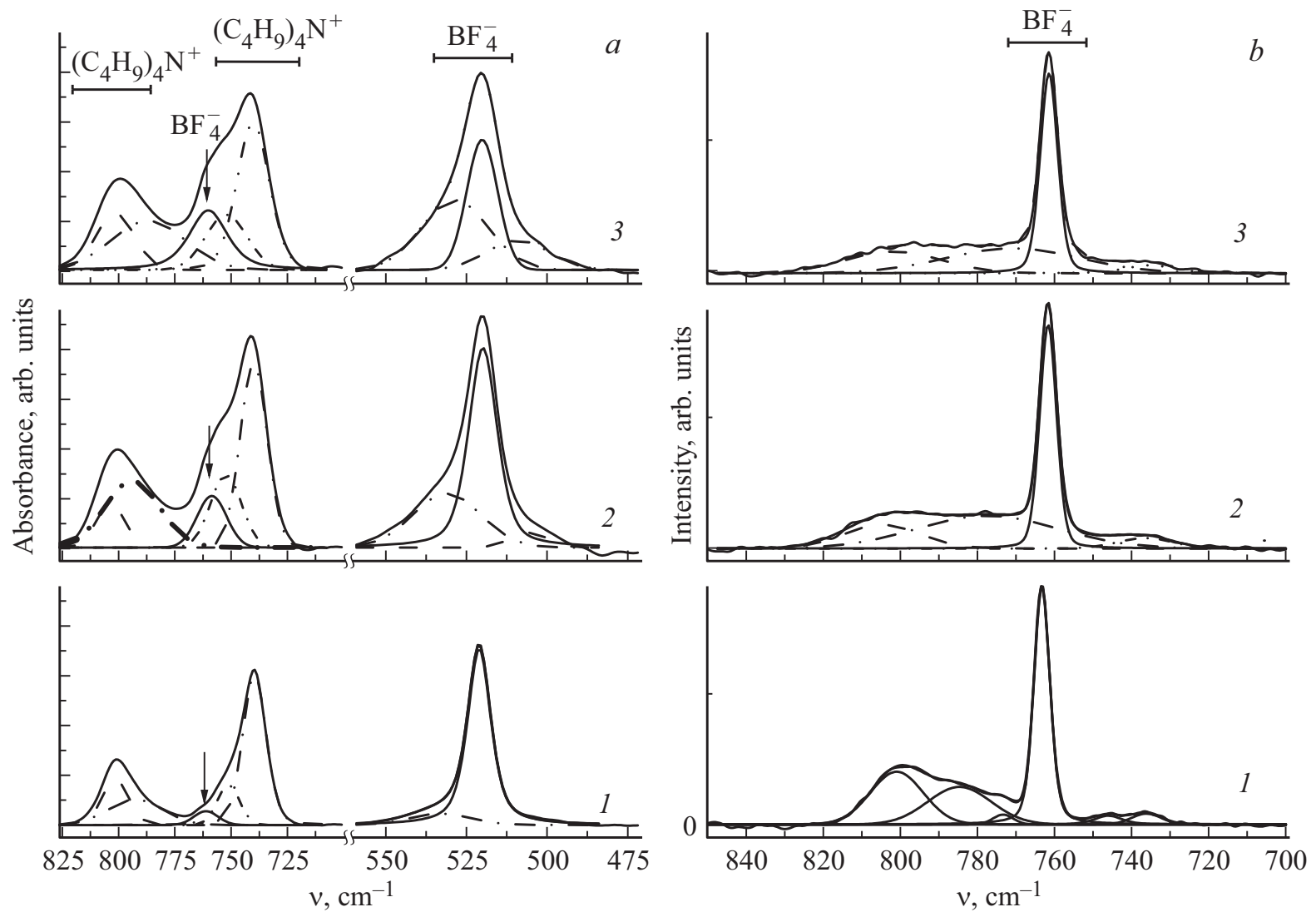

Рис. 1. Спектры ИК поглощения тетрафторборат иона в диапазоне частот колебаний $v_{1}\left(A_{1}\right)$ и $v_{4}\left(F_{1}\right)(a)$ и комбинационного рассеяния $($ КР $)$ в области колебания $v_{1}\left(A_{1}\right)(b)$ и результаты их разложения на компоненты при различных температурах: 1) $t=25^{\circ} \mathrm{C}$; 2) $t=65^{\circ} \mathrm{C}$; 3) $t=145^{\circ} \mathrm{C}$.

нием специальной нагревательной ячейки в диапазоне температур от комнатной до $200^{\circ} \mathrm{C}$.

\section{3. Результаты и обсуждение}

Свободный тетрафторборат ион $\mathrm{BF}_{4}^{-}$обладает симметрией $T_{d}$ и имеет девять колебательных степеней свободы, распределенных между четырьмя нормальными колебаниями: полносимметричным валентным $v_{1}\left(A_{1}\right)$ $\left(\sim 760 \mathrm{~cm}^{-1}\right)$, деформационным $v_{2}(E)\left(\sim 360 \mathrm{~cm}^{-1}\right)$, антисимметричным валентным $v_{3}\left(F_{2}\right)\left(\sim 1100 \mathrm{~cm}^{-1}\right)$ и деформационным $v_{4}\left(F_{1}\right)\left(\sim 520 \mathrm{~cm}^{-1}\right)$ [7,8]. Теоретикогрупповой анализ внутримолекулярных колебаний $\mathrm{BF}_{4}^{-}$ показывает, что в ИК-спектре изолированного $\mathrm{BF}_{4}^{-}$ должны быть активны только два колебания - $v_{3}\left(F_{2}\right)$ и $v_{4}\left(F_{1}\right)$, а в спектре КР активны все девять, наиболее интенсивны $-v_{1}\left(A_{1}\right)$ и $v_{2}(E)$.

Колебательный спектр $\mathrm{BF}_{4}^{-}$показывает, что форма полос отвечающих внутренним колебаниям имеют сложное строение, они состоят более чем из одной компоненты. Из рис. $1, a$ видно, что в спектральной области $700-850 \mathrm{~cm}^{-1}$, помимо полос колебаний, относящихся к колебаниям иона тетрабутиламмония [9], наблюдается асимметричное искажение кон- тура линии с максимумом при $760 \mathrm{~cm}^{-1}$ с высокочастотной стороны, а с ростом температуры контур указанной полосы увеличивается интегральная интенсивность. Аналогичная ситуация имеет место и в случае контура полосы $v_{4}\left(F_{1}\right) \sim 525 \mathrm{~cm}^{-1}$ в ИК-спектре. Подобные явления наблюдались и ранее и связываются они с наличием в кристалле ориентационно-разупорядоченных анионов, характеризующихся более развитой реориентационной подвижностью [10-13]. Наличие ориентационно-разупорядоченной фазы у тетрафторборат тетра-н-бутиламмония в области $62-160^{\circ} \mathrm{C}$ подтверждено также данными термического, рентгенофазового анализа [14]. Поэтому можно допустить, что поворотнорелаксационный механизм является главным фактором, обуславливающим температурное уширение колебательных полос в ИК-спектрах исследуемой соли.

На рис. 2. приведены температурно-фазовые зависимости положения максимумов и полуширин некоторых полос в ИК- и КР-спектрах тетрафторборат аниона. Частоты внутренних колебаний $v_{1}$ и $v_{4}$ с ростом температуры линейно смещаются в сторону меньших волновых чисел (либо остаются практически неизменными) и испытывают скачкообразное изменение при температуре фазового перехода. Температурная зависимость полуширин колебательных полос близка экспоненте. 

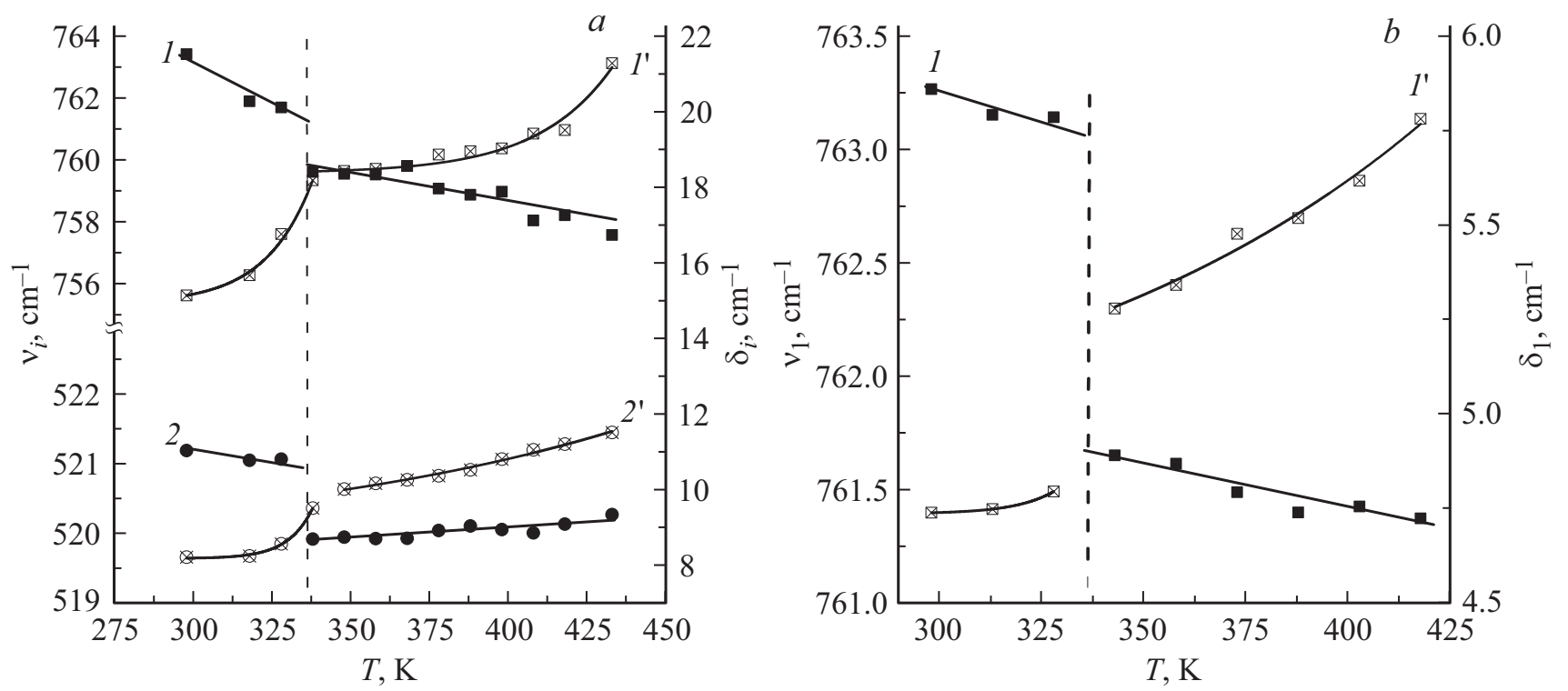

Рис. 2. Температурно-фазовая зависимость частот и полуширин линий тетрафторборат иона в ИК $(a)$ и в КР $(b)$ спектрах н-Bu $\mathrm{NBF}_{4}: 1-v_{1}\left(A_{1}\right) ; 1-v_{1}\left(A_{1}\right) ; 1^{\prime}-\delta v_{1} ; 2-v_{4}\left(F_{1}\right) ; 2^{\prime}-\delta v_{4}$.

Для оценки значений времен переориентации $\mathrm{BF}_{4}^{-}$ мы воспользовались методом, предложенным в [15], согласно которому время ориентационной релаксации может быть оценена как разность

$$
\tau_{1}^{\text {or }}=\left[\pi c\left(\delta_{\mathrm{IR}}-\delta_{\text {raman }}\right)\right]^{-1},
$$

где $\tau_{\mathrm{IR}}$ и $\tau_{\text {raman }}-$ полуширина ИК-полосы поглощения и полуширина сильно поляризованной линии КР, отвечающие одному и тому же полносимметричному колебанию $\mathrm{BF}_{4}^{-}, c-$ скорость света. Этот метод основан на том, что форма контуров сильно поляризованных линий в спектрах КР всецело обусловлена процессами колебательной релаксации (степень поляризации $\mathrm{BF}_{4}^{-}$иона $\rho \sim 0.05)$, в то время как соответствующая ИК-полоса дополнительно уширяется за счет переориентаций. Наши оценочные расчеты времен переориентаций $-\tau_{1}^{\text {or }}$ и их сравнение с соответствующими значениями для свободных ротаторов $\left(\tau_{\mathrm{FR}}=(68 / 360) 2 \pi(I / k T)^{1 / 2}\right.$, где
$I=1.65 \cdot 10^{-45} \mathrm{~kg} \cdot \mathrm{m}^{2}-$ момент инерции $\mathrm{BF}_{4}^{-}$иона) и временами бинарных столкновений $\tau_{\mathrm{BC}}=I /\left(2 k T \tau_{1}^{\text {or }}\right)$ систематизированы в таблице. Также определен угловой шаг диффузии по $\varepsilon=\tau_{\mathrm{BC}}^{*} \omega$, где $\dot{\omega}=(k T / I)^{1 / 2}-$ средняя скорость вращения аниона.

Для сравнительной оценки энергетических параметров переориентации о $\mathrm{BF}_{4}^{-}$иона в обеих фазах были рассчитаны соответствующие величины потенциальных барьеров переориентаций. Согласно теории [16], поворотное движение молекулы в твердом теле совершается путем ротационных перескоков частицы из одного положения равновесия в другое, которое характеризуется временем переориентации

$$
\tau_{1}^{\text {or }}=\tau_{0} \exp \left(U_{\text {reor }} / R T\right)
$$

где $\tau_{0}-$ полупериод вращательных качаний частицы около положения равновесия; $U_{\text {or }}-$ потенциальный барьер, определяющий два соседних положения

Параметры ионно-поворотной динамики $\mathrm{BF}_{4}^{-}$иона в системе н-Bu $4 \mathrm{NBF}_{4}$

\begin{tabular}{c|l|l|l|l|l|l|l|l}
\hline $\mathrm{T}$, & \multicolumn{1}{|c|}{$\begin{array}{c}\delta_{\mathrm{IR}}, \\
\mathrm{cm}\end{array}$} & $\begin{array}{c}\delta_{\text {raman, }} \\
\mathrm{cm}^{-1}\end{array}$ & $\begin{array}{c}\tau_{1}^{\text {or }}, \\
10^{-12} \mathrm{~s}\end{array}$ & $\begin{array}{c}\tau_{\mathrm{FR},} \\
10^{-14} \mathrm{~s}\end{array}$ & $\begin{array}{c}\tau_{\mathrm{BC},} \\
10^{-14} \mathrm{~s}\end{array}$ & $\begin{array}{c}\tau_{1}^{\text {or }} / \tau_{\mathrm{FR}} \\
\tau_{1}^{\text {or }} / \tau_{\mathrm{BC}}\end{array}$ & $\begin{array}{c}\varepsilon, \\
\mathrm{degree}\end{array}$ \\
\hline 298 & 15.1 & 4.74 & 1.02 & 75.1 & 19.58 & 1.36 & 5.2 & 17.7 \\
313 & 15.6 & 4.75 & 0.97 & 73.3 & 19.58 & 1.3 & 4.98 & 18.1 \\
328 & 16.76 & 4.79 & 0.89 & 71.6 & 20.47 & 1.24 & 4.35 & 19.41 \\
343 & 18.18 & 5.27 & 0.82 & 70.03 & 21.11 & 1.178 & 3.91 & 20.51 \\
358 & 18.48 & 5.34 & 0.81 & 68.5 & 20.6 & 1.18 & 3.9 & 20.46 \\
373 & 18.86 & 5.47 & 0.79 & 67.16 & 20.1 & 1.18 & 3.95 & 20.4 \\
388 & 18.9 & 5.52 & 0.79 & 65.8 & 19.4 & 1.2 & 4.08 & 20.1 \\
403 & 19.4 & 5.6 & 0.77 & 64.6 & 19.22 & 1.19 & 4.01 & 20.2 \\
418 & 19.51 & 5.78 & 0.77 & 63.4 & 18.44 & 1.22 & 4.205 & 19.8
\end{tabular}




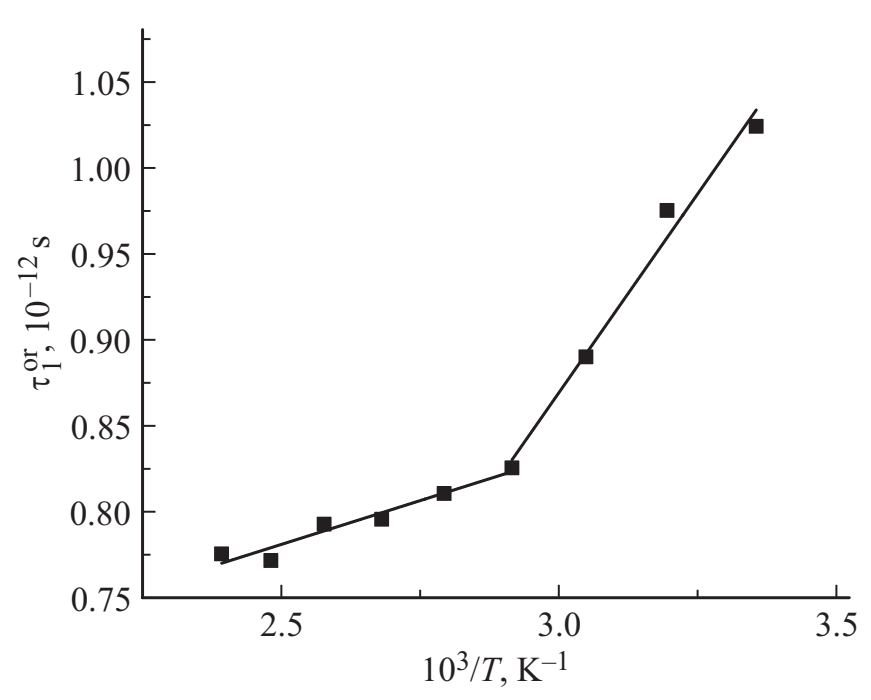

Рис. 3. Зависимость времени переориентации тетрафторборат-иона от температуры.

равновесия. Расчет энергии переориентации, проведенный из температурной зависимости времени переориентации $\tau_{1}^{\text {reor }}$ (рис. 3) показал, что для кристаллической фазы $U_{\mathrm{or}}^{\text {cryst }}=4.1 \mathrm{~kJ} / \mathrm{mol}$, а для пластической фазы $U_{\text {or }}^{\text {plast }}=1 \mathrm{~kJ} / \mathrm{mol}$. Как видно из проведенных расчетов пластическая фаза $\mathrm{H}-\mathrm{Bu}_{4} \mathrm{NBF}_{4}$ характеризуется существенным низким уровнем потенциального барьера препятствующего переориентации терафторборат иона, а отношение $\tau_{1}^{\text {or }} / \tau_{\mathrm{FR}}$ близко к 1 . Иными словами реориентационное движение аниона в пластической фазе носит характер квазисвободного вращения. Здесь необходимо отметить некоторые специфические особенности структурных единиц исследуемой органической соли от изученных ранее $[1,17-20]$ неорганических солей щелочных металлов (нитраты, нитриты, перренаты). Дело в том, что в неорганических солях имеют место сильные кулоновские анион катионные взаимодействия, которые обеспечивают стабильность кристаллической решетки в широком температурном диапазоне. В органической соли н-Bu $\mathrm{NBF}_{4}$ в силу больших размеров катиона положительный заряд как бы „размазан“ по большой поверхности и межионные кулоновские взаимодействия в нем существенно слабее. Это в свою очередь должно способствовать росту трансляционной и ориентационной подвижности тетрафторборат анионов, что и наблюдается в эксперименте - увеличение ионной проводимости (рост трансляционной подвижности), уменьшение времен и барьеров переориентации (рост ориентационной подвижности). Более того само формирование пластической фазы в н-Bu $4 \mathrm{NBr}$ можно связать с различием динамических свойств анионной и катионной подсистем, а именно в исследуемой соли мы имеем относительно неподвижный катионный остов как бы „плавающий“ в подвижной анионной подсистеме.

\section{4. Заключение}

Таким образом, описывая ионную динамику в органической соли н-Bu $\mathrm{NBF}_{4}$, можно сказать, что в пластической фазе тетрафторборат-ион характеризуется наиболее развитой реориентационной подвижностью, в то время как катионная подсистема с учетом больших размеров катионов составляет менее подвижный остов кристаллической решетки.

\section{Список литературы}

[1] К.Ш. Рабаданов, М.М. Гафуров, А.Р. Алиев, И.Р. Ахмедов, М.Г. Какагасанов, С.А. Кириллов. Расплавы 3, 67 (2011).

[2] M.M. Gafurov, A.R. Aliev. Spectrochim. Acta. A 60, 1549 (2004).

[3] И.Д. Закирьянова, П.А. Архипов, Д.О. Закирьянов. Журн. прикл. спектроскопии 82, 841 (2015).

[4] D.O. Tretyakov, V.D. Prisiazhnyi, M.M. Gafurov, K.Sh. Rabadanov, S.A. Kirillov. J. Chem. Eng. Data 55, 1958 (2010).

[5] М.М. Гафуров, В.Д. Присяжный, А.Р. Алиев. Укр. хим. журн. 56, 1244 (1990).

[6] Н.Г. Парсонидж, Л.А. Стейвли. Беспорядок в кристаллах. Мир, М. (1982). 434 с.

[7] К. Накамото. ИК-спектры и спектры КР неорганических и координационных соединений / Пер. с англ. Мир, М. (1991). $536 \mathrm{c.}$

[8] И.С. Перелыгин, Г.П. Михайлов. Журн. прикл. спектроскопии 55, 153 (1991).

[9] Z. Javanshir, K. Mehrani, S. Ghammamy, L. Saghatforoush, S. Seyedsadjadi, A. Hassanijoshaghani, H. Tavakol. Bull. Korean Chem. Soc. 29, 1464 ( 2008).

[10] С.В. Карпов, А.А. Шултин. Термоактивационные процессы и колебательные спектры кристаллов со сложными ионами. В кн.: Колебания оксидных решеток. Наука, Л. (1980). $302 \mathrm{c}$

[11] С.В. Карпов, А.А. Шултин. ФТТ 17, 2868 (1975).

[12] M.H. Brooker, D.E. Irish. Canad. J. Chem. 49, 1289 (1971).

[13] М.М. Гафуров. ФТТ 26, 1186 (1984).

[14] Н.Ф. Уваров, А.А. Искакова, Н.В Булина, К.Б. Герасимов, А.Б. Слободюк, В.Я. Кавун. Электрохимия 51, 564 (2015).

[15] Г.П. Буян, В.Е. Погорелов, И.И. Кондиленко. Оптика и спектроскопия 27, 248 (1969).

[16] Я.И. Френкель. Кинетическая теория жидкостей. Наука, Л. (1975). 592 c.

[17] М.М. Гафуров, А.З. Гаджиев, В.Д. Присяжный. В сб.: Ионные расплавы и твердые электролиты. Наук. думка, Киев (1989). Вып. 4. С. 13-26.

[18] М.М. Гафуров, А.Р. Алиев, В.Д. Присяжный. Укр. хим. журн. 66, 96 (2000).

[19] М.М. Гафуров, А.Р. Алиев. Журн. структур. химии 46, 856 (2005).

[20] M.M. Gafurov, A.R. Aliev, M.B. Ataev, K.Sh. Rabadanov. Spectrochim. Acta. Part A 114, 563 (2013).

Редактор Т.Н. Василевская 